\title{
Efficient rhizosphere colonization by Pseudomonas fluorescens f113 mutants unable to form biofilms on abiotic surfaces
}

\author{
Emma Barahona, ${ }^{1 \dagger}$ Ana Navazo, ${ }^{1 \dagger}$ \\ Fátima Yousef-Coronado, ${ }^{2}$ Daniel Aguirre de Cárcer, ${ }^{1}$ \\ Francisco Martínez-Granero, ${ }^{1}$ \\ Manuel Espinosa-Urgel, ${ }^{2}$ Marta Martín ${ }^{1}$ and \\ Rafael Rivilla ${ }^{1 *}$ \\ ${ }^{1}$ Departamento de Biología, Universidad Autónoma de \\ Madrid, 28049 Madrid, Spain. \\ ${ }^{2}$ Departamento de Protección Ambiental, Estación \\ Experimental del Zaidín, CSIC, 18008 Granada, Spain.
}

\section{Summary}

Motility is a key trait for rhizosphere colonization by Pseudomonas fluorescens. Mutants with reduced motility are poor competitors, and hypermotile, more competitive phenotypic variants are selected in the rhizosphere. Flagellar motility is a feature associated to planktonic, free-living single cells, and although it is necessary for the initial steps of biofilm formation, bacteria in biofilm lack flagella. To test the correlation between biofilm formation and rhizosphere colonization, we have used $P$. fluorescens F113 hypermotile derivatives and mutants affected in regulatory genes which in other bacteria modulate biofilm development, namely gacS (G), sadB (S) and wspR (W). Mutants affected in these three genes and a hypermotile variant (V35) isolated from the rhizosphere were impaired in biofilm formation on abiotic surfaces, but colonized the alfalfa root apex as efficiently as the wild-type strain, indicating that biofilm formation on abiotic surfaces and rhizosphere colonization follow different regulatory pathways in $P$. fluorescens. Furthermore, a triple mutant gacSsadBwspR (GSW) and V35 were more competitive than the wild-type strain for root-tip colonization, suggesting that motility is more relevant in this environment than the ability to form biofilms on abiotic surfaces. Microscopy showed the same root colonization pattern for $P$. fluorescens $\mathrm{F} 113$ and all the derivatives: extensive microcolonies, apparently held to the rhizoplane by a

Received 10 February, 2010; accepted 25 May, 2010. *For correspondence. E-mail rafael.rivilla@uam.es; Tel. (+34) 914978 188; Fax (+34) 914978344 . ${ }^{\dagger}$ E.B and A.N. contributed equally to this work. mucigel that seems to be plant produced. Therefore, the ability to form biofilms on abiotic surfaces does not necessarily correlates with efficient rhizosphere colonization or competitive colonization.

\section{Introduction}

The rhizosphere is the portion of soil that is influenced by plant roots and is characterized by harbouring a higher number of microorganisms than bulk soil (Hiltner, 1904). Numerous bacteria, generally termed rhizobacteria, are adapted to this ecosystem. Rhizobacteria can affect plant fitness and are also important in biotechnological applications based on integrated plant-bacteria systems. The fluorescent pseudomonads group include several species of rhizobacteria that have been used as model strains for rhizosphere colonization experiments (Lugtenberg and Dekkers, 1999; Lugtenberg et al., 2001) and for applications such as biocontrol (Haas and Defago, 2005) and rhizoremediation (Yee et al., 1998). Pseudomonas fluorescens $\mathrm{F} 113$ was isolated from the sugar-beet rhizosphere and is able to protect plants against the oomycete Pythium ultimum by means of the production of the fungicide 2, 4-diacetylphloroglucinol (DAPG) (Shanahan et al., 1992). It has also been genetically modified for PCB degradation and tested in rhizoremediation experiments (Brazil et al., 1995; Villacieros et al., 2005; Aguirre de Cárcer et al., 2007a,b). Pseudomonas fluorescens F113 has been shown to colonize the rhizosphere of a variety of plants including pea (Naseby and Lynch, 1999), tomato (Dekkers et al., 2000), willow (Aguirre de Cárcer et al., 2007a) and alfalfa (Villacieros et al., 2003). Colonization studies on alfalfa have shown that this bacterium establishes on the rhizoplane (root surface) forming extensive microcolonies (Villacieros et al., 2003). This type of colonization pattern has also been observed for other fluorescent pseudomonads on tomato roots (Chin-A-Woeng et al., 1997).

The transition between the sessile lifestyle that biofilms represent and a planktonic, motile lifestyle is controlled in numerous bacteria by the levels of the second messenger cyclic di-GMP. These levels are in turn regulated by the activity of proteins containing diguanilate cyclase (GGDEF domains) and phosphodiesterase (EAL or 
HD-GYP domains) activities (for a recent review see Hengge, 2009). Low c-di-GMP levels are associated with a free living, motile phenotype while high c-di-GMP levels lead to biofilm formation and reduced motility.

Although flagella are required for the first steps of biofilm formation (O'Toole and Kolter, 1998a), flagelladriven motility can be viewed as an opposing lifestyle to that of biofilms. In fact, expression of flagellar genes is repressed in biofilms of $P$. aeruginosa or Bacillus subtilis (Lazazzera, 2005). Motility has been recognized as one of the most important traits required for rhizosphere colonization by $P$. fluorescens and other bacteria, since nonmotile and non-chemotactic mutants are among the most impaired in competitive root colonization (de Weert et al., 2002), and a wild-type level of motility is required by $P$. fluorescens for competitive rhizosphere colonization (Capdevila et al., 2004). The importance of motility for rhizosphere colonization by $P$. fluorescens is highlighted by the finding that the rhizosphere selects for phenotypic variants (Sanchez-Contreras et al., 2002), which harbour mutations in the genes encoding the two-component system GacA/GacS, and in other unidentified genes, resulting in a gradation of hypermotility phenotypes (Martínez-Granero et al., 2006).

In this work, we have used $P$. fluorescens F113 hypermotile phenotypic variants isolated from the rhizosphere and hypermotile mutants affected in the gacS, sadB and $w s p R$ genes, which have been implicated in biofilm formation, to test its importance in root colonization and competitive root colonization.

\section{Results}

\section{Biofilm formation by hypermotile mutants and phenotypic variants}

In a previous study investigating motility repressors we found that several of the hypermotile mutants isolated were affected in genes that had been described as implicated in biofilm formation in different pseudomonads (Navazo et al., 2009). To investigate whether they had a similar role in $P$. fluorescens $\mathrm{F} 113$, the gacS, wspR and sadB mutants were tested for biofilm formation on abiotic surfaces using a standard crystal violet test on two different plastic surfaces. As shown in Fig. $1 \mathrm{~A}$, the three mutants are impaired in biofilm formation on both surfaces, showing a substantial reduction on crystal violet staining when compared with the wild-type strain. Double and triple mutants were also tested for biofilm formation and an additive phenotype was observed (Fig. 1A), except in the case of the double sadBgacS (SG) mutant, which shows an intermediate phenotype. However, the additive phenotype of all other mutants, including the triple gacSsadBwspR (GSW) mutant, suggests that the three mutants were affected in different pathways regulating biofilm formation. The GSW triple mutant was almost unable to form biofilms (five times reduction, as compared with the wild-type strain) on these surfaces and presented a swimming phenotype very similar to variant 35 (V35) (Fig. 2A), a hypermotile phenotypic variant of F113 isolated from the alfalfa rhizosphere (MartinezGranero et al., 2006). For this reason we also tested V35 for biofilm formation in the same systems resulting in an almost complete inability to form biofilms (five times reduction). It is interesting to note that according to this test, GSW and V35 are more affected in biofilm formation than the non-motile, aflagellated mutant fliC (Capdevila et al., 2004), a mutant affected in initial attachment because of the lack of flagella.

Biofilm formation ability of the wild-type strain and the most affected strains (V35 and the GSW mutant) was also tested under flow conditions. Table 1 shows the parameters of the biofilms formed after 3 and $6 \mathrm{~h}$ by the three strains. Similarly to the static biofilm experiments, flow-cell biofilms formed by V35 and the triple mutant presented a more than 10 times reduction in biomass, average thickness and maximum thickness, compared with the wildtype strain, indicating again a severe defect on biofilm formation. According to these parameters, V35 was the most affected strain, with values between 19- and 49-folds lower than the wild-type strain, after $6 \mathrm{~h}$. Confocal microscopy observation also showed that the wildtype strain (Fig. 1B) formed thick three-dimensional biofilms after $6 \mathrm{~h}$. No three-dimensional structures, but only isolated attached cells were observed for V35, while the triple mutant attached forming small clusters of cells. Differences were also evident at later time points. After $24 \mathrm{~h}$, the wild-type maintained a thicker, structured biofilm, whereas V35 was the most affected strain and did not progress beyond a monolayer of cells on the surface.

Fig. 1. Biofilm forming ability of $P$. fluorescens $\mathrm{F} 113$ and derivatives on abiotic surfaces.

A. Static biofilm assay. Biofilms were measured as the amount of crystal violet absorbed by the biofilm formed on multi-well plates and determined by absorbance at $590 \mathrm{~nm}$ after de-staining with ethanol (see methods). Absorbance of the wild-type strain was arbitrarily given a value of 1. Averages and standard deviations of eight replicas per strain corresponding to three independent experiments are shown. Different letters indicate a significant difference $(P<0.05)$. Black bars correspond to experiments performed on polystyrene plates and grey bars to experiments on polypropylene.

B. Flow-cell assay. Upper row from left to right F113, after 6 h; V35, after 6 h; Triple mutant GSW, after 6 h. Lower row, from left to right F113, after $24 \mathrm{~h}$.; V35, after $24 \mathrm{~h}$.; GSW, after $24 \mathrm{~h}$. Bar represents $50 \mu \mathrm{m}$. Mature, three-dimensional structures were only observed in the case of the wild-type strain F113. 


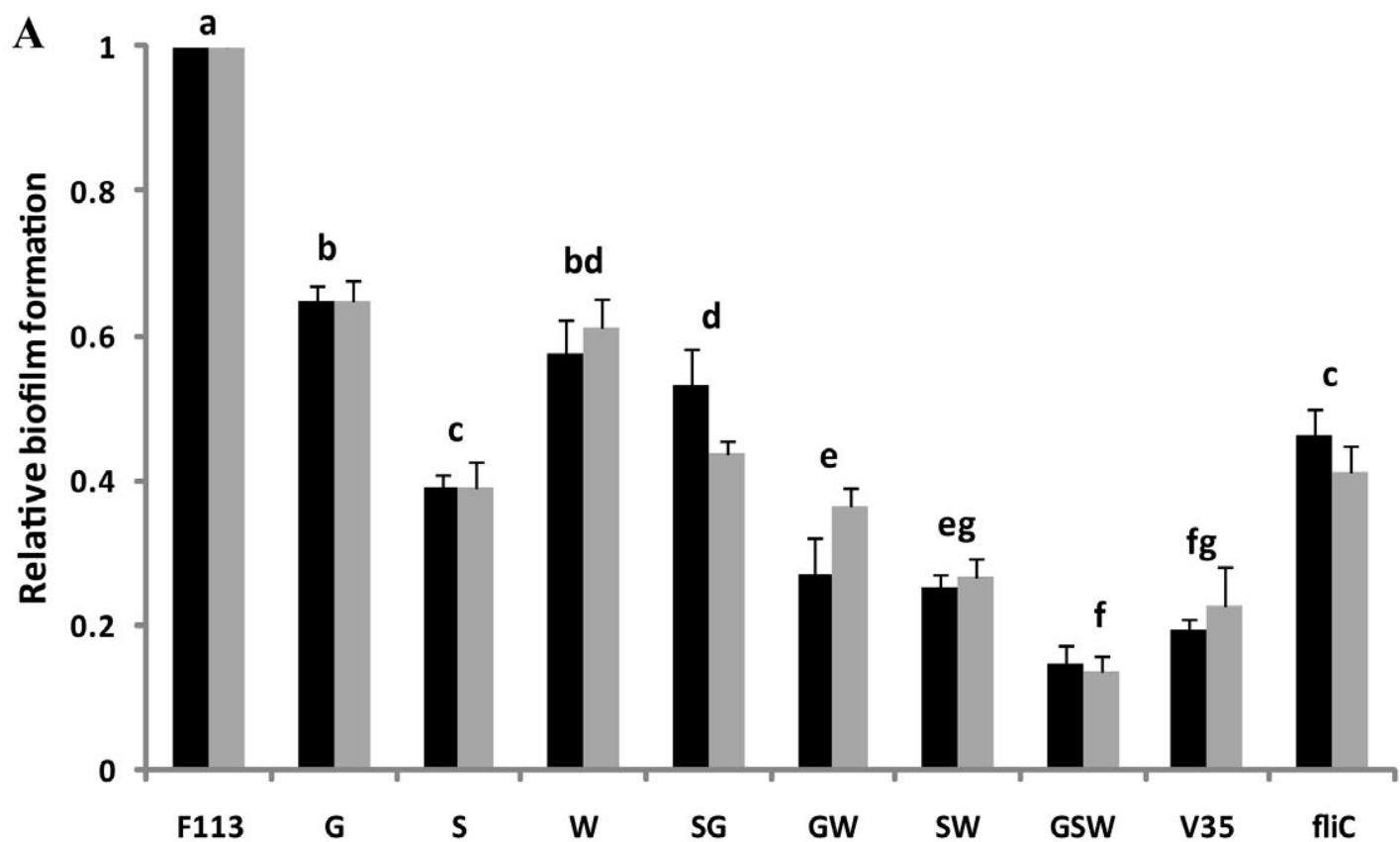

B
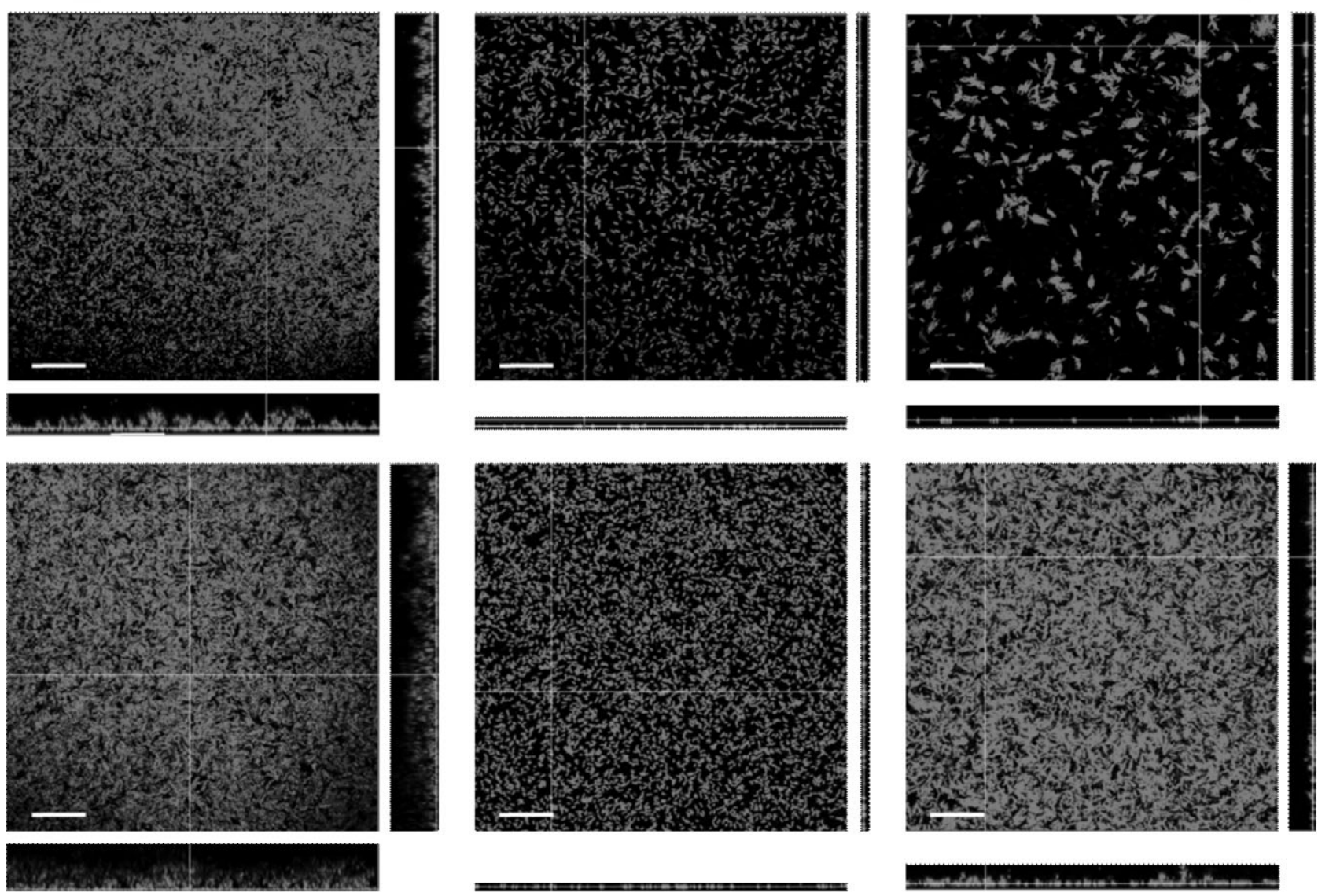

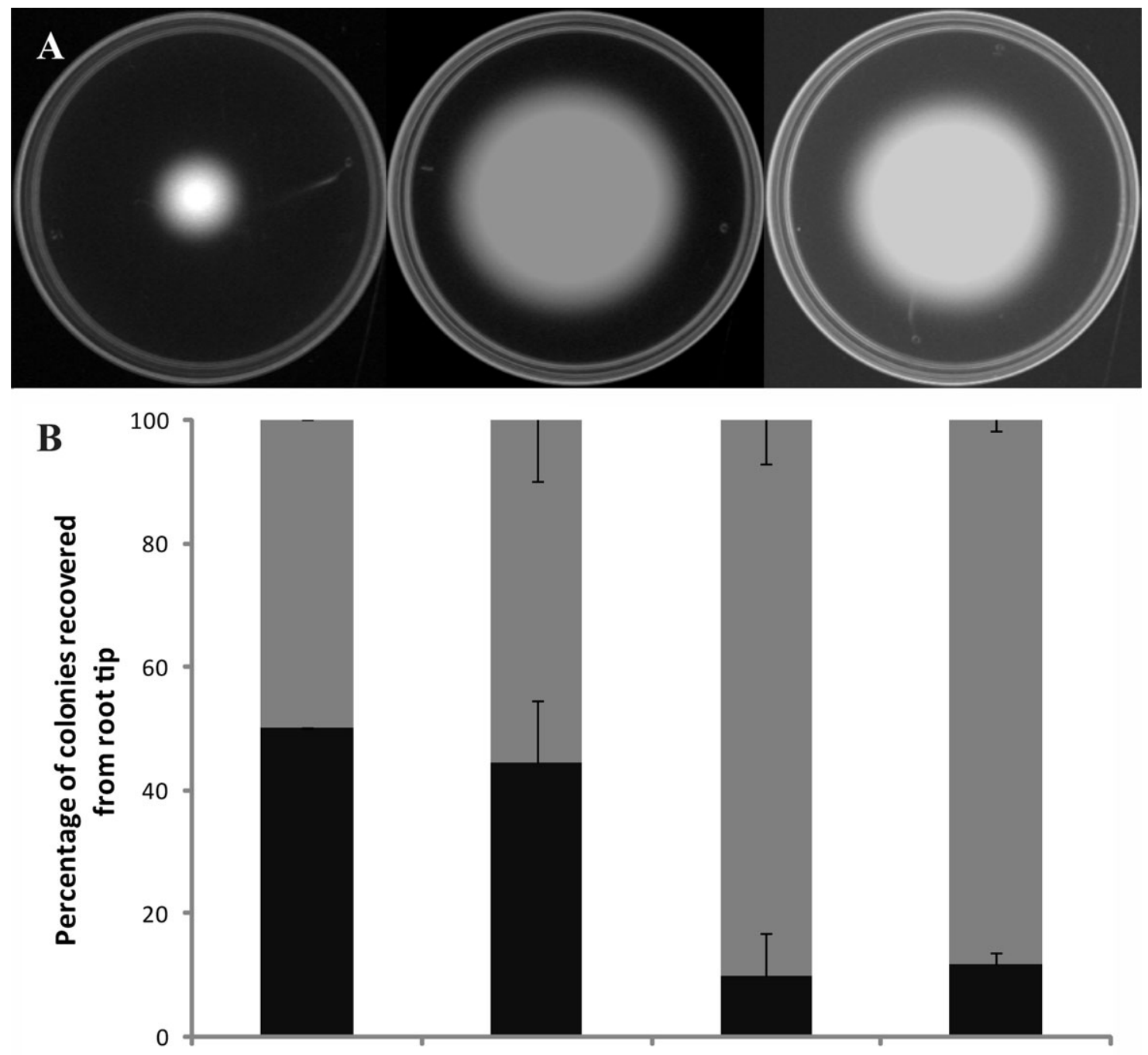

$\mathrm{F} 113 / \mathrm{F} 113 \mathrm{~km}$
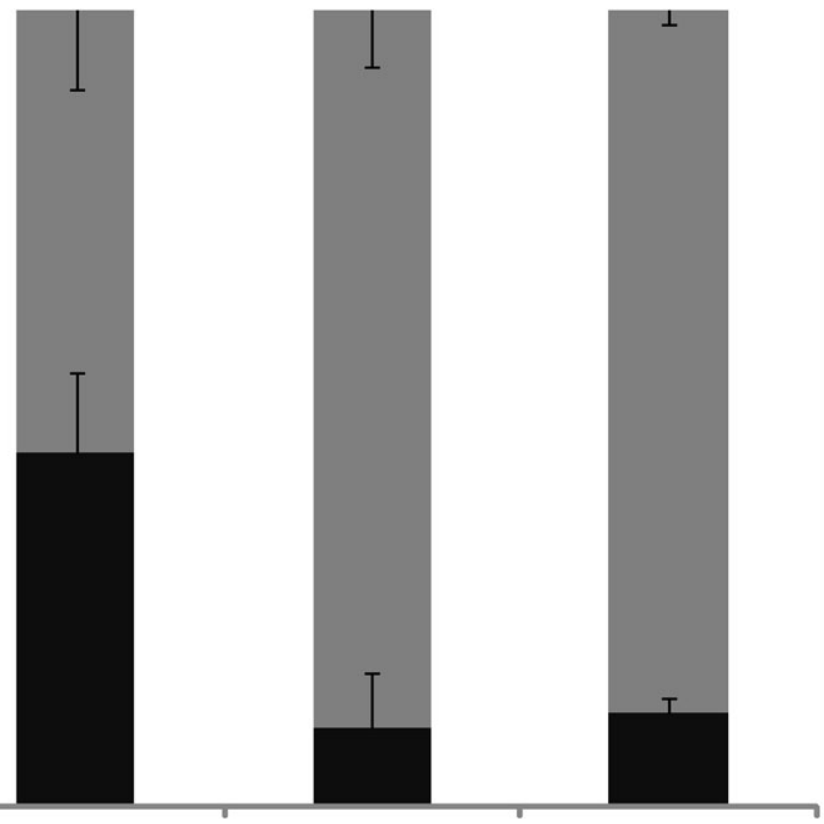

Fig. 2. Swimming motility phenotype and competitive alfalfa rhizosphere colonization by F113 derivatives.

A. Swimming motility. Haloes produced by the wild-type strain, the GSW mutant and V35 after $18 \mathrm{~h}$. Bacterial cells were inoculated with a sterile toothpick just below the surface of a plate containing SA medium supplemented with $0.3 \%$ purified agar. Plates were incubated $18 \mathrm{~h}$ at $28^{\circ} \mathrm{C}$. Average halo diameter was 14,40 and $42 \mathrm{~mm}$ for the wild-type strain, the GSW mutant and V35 respectively.

B. Competitive rhizosphere colonization. The wild-type strain was used as the competitor in all the experiments. Plants were inoculated 1:1 with the test strain and the competitor and after 2 weeks root tips were collected and the bacteria present plated. Grey bars represent the percentage of colonies recovered from the tested strains; black bars represent the percentage of colonies recovered from the competitor (wild-type) strain. Arithmetic means and standard deviation are presented. The gacS and sadB mutants gave results similar to the wspR mutant.

Table 1. Biofilm parameters.

\begin{tabular}{|c|c|c|c|c|c|c|}
\hline & \multicolumn{2}{|c|}{ F113 } & \multicolumn{2}{|c|}{ V35 } & \multicolumn{2}{|c|}{ GSW } \\
\hline & $3 \mathrm{~h}$ & $6 \mathrm{~h}$ & $3 \mathrm{~h}$ & $6 \mathrm{~h}$ & $3 \mathrm{~h}$ & $6 \mathrm{~h}$ \\
\hline Biomass (volume cells per surface) & $4.40 \pm 0.9$ & $8.11 \pm 3.20$ & $0.35 \pm 0.15$ & $0.30 \pm 0.08$ & $0.09 \pm 0.06$ & $0.34 \pm 0.08$ \\
\hline Average thickness $(\mu \mathrm{m})$ & $3.56 \pm 1.01$ & $8.36 \pm 2.79$ & $0.21 \pm 0.12$ & $0.17 \pm 0.06$ & $0.06 \pm 0.05$ & $0.27 \pm 0.06$ \\
\hline Maximum thickness $(\mu \mathrm{m})$ & $25.33 \pm 14.97$ & $35.92 \pm 16.85$ & $1.69 \pm 0.48$ & $1.90 \pm 0.32$ & $5.88 \pm 1.24$ & $7.88 \pm 1.73$ \\
\hline
\end{tabular}


Strain GSW showed a somewhat intermediate phenotype, showing some structure, but not forming a mature biofilm. Figures $\mathrm{S} 1$ and $\mathrm{S} 2$ show the three-dimensional reconstruction of the biofilm formed on flow-cells by the wild-type and V35. These results clearly show that the gacA, sadB and wspR genes are required for full biofilm formation, being implicated in independent pathways.

\section{Rhizosphere colonization and competitive colonization}

Rhizosphere colonization experiments showed that none of the mutants or the phenotypic variants was impaired in root-tip colonization (c. $10^{7} \mathrm{cfu}^{-1}$ root-tip), and no differences with the wild-type strain were observed. No differences were observed in whole root colonization assays (data not shown). It is important to note that under these laboratory conditions even the most affected mutants in competitive colonization are able to colonize the rhizosphere when individually inoculated. This has been previously shown for non-motile (Capdevila et al., 2004) and non-chemotactic mutants (de Weert et al., 2002).

Competitive colonization experiments (Fig. 2B) between the wild-type strain and any of the single mutants showed no differences, and strains were recovered from the root tip at a 1:1 proportion. However, differences were obtained when either V35 or the GSW triple mutant were tested against the wild-type strain. As shown in Fig. 2B, these strains were able to displace the wild-type strain from the root-tip, showing that the strains that were more affected in biofilm formation on abiotic surfaces were even more competitive than the wild-type strain in root-tip colonization. These data indicate that motility, rather than the ability to form mature biofilms on abiotic surfaces, is a key trait for the competitive efficiency of $P$. fluorescens F113 with respect to root tip colonization.

To analyse if the hypermotile, biofilm-defective phenotype causes an altered colonization pattern, the wild-type strain and the most affected strain in biofilm formation (V35) were tagged with plasmids producing constitutive expression of gfp. Rhizosphere colonizing cells were observed by epifluorescence microscopy. Figure 3 shows that both strains form the same structures on the rhizoplane and no differences can be observed between them either in colonization sites or in the shape, size or abundance of the microcolonies. In order to analyse colonization at a higher detail, scanning electron microscopy was also used. Figure 4 shows that both strains extensively colonized the rhizoplane and no differences were observed between them. Interestingly, bacterial cells appear tightly packed in microcolonies, and no extracellular matrix, typical of a mature biofilms could be observed between bacterial cells. This extracellular matrix is usually visualized as fibrils interconnecting bacteria. No such fibrils were observed in microcolonies formed by either strain. Instead, bacteria appear to be covered and held to the plant surface by what seems to be a mucigel layer of plant origin (Chin-A-Woeng et al., 1997).

\section{Discussion}

Fluorescent pseudomonads have been studied as model microorganisms in their interaction with the roots (Lugtenberg and Dekkers, 1999; Lugtenberg et al., 2001) and have been found forming dense biofilm-like structures that occupy the rhizoplane, especially at junctions between epidermal root cells (Chin-A-Woeng et al., 1997; Normander et al., 1999; Cassidy et al., 2000; Ramos et al., 2000; Villacieros et al., 2003). Biofilm formation is a complex process and different strains develop different biofilm architectures, depending also on environmental conditions. Preliminary studies by O'Toole and Kolter (1998b) showed that several $P$. fluorescens mutants were unable to form fully developed biofilms because they were affected in the initial attachment step. These mutants were termed sad (surface attachment defective) and included $s a d B$. The $s a d B$ gene encodes a protein proposed to participate in c-di-GMP sensing (Kuchma et al., 2007; Merrit et al., 2007), and it has been shown that $s a d B$ mutants are impaired in the transition from reversible to irreversible attachment during biofilm formation (Caiazza and O'Toole, 2004). We have shown here that in $P$. fluorescens the hypermotile sadB mutant (Navazo et al., 2009) shows reduced biofilm formation on abiotic surfaces. However, this mutant is not defective in competitive root tip colonization, and no differences in colonization were observed when compared with the wild-type strain. Similarly, Hickman and colleagues (2005) reported that mutations in the wspR gene, which encodes a diguanilate cyclase, resulted in reduced biofilm formation by $P$. aeruginosa. In $P$. fluorescens $\mathrm{F} 113$ the wspR mutant is hypermotile (Navazo et al., 2009) and we have shown here that it is also negatively affected in biofilm formation but not in rhizosphere colonization. A sadBwspR double mutant displays a significant reduction of its ability to form biofilms on abiotic surfaces. The fact that the phenotype of the double mutant is additive suggests that $s a d B$ and $w s p R$ influence biofilm formation by two independent pathways. A similar result was found for swimming and swarming motility (Navazo et al., 2009).

Besides c-di-GMP regulation of biofilm formation, other signalling pathways have been proposed to be involved in the transition to this lifestyle. The two-component system formed by GacS and GacA post-transcriptionally regulates multiple traits related to secondary metabolism. The regulatory mechanism is complex and involves the titration of RNA binding proteins (RsmAE) by small RNAs transcriptionally induced by GacA. In the absence of these small RNAs, the Rsm proteins block the translation 

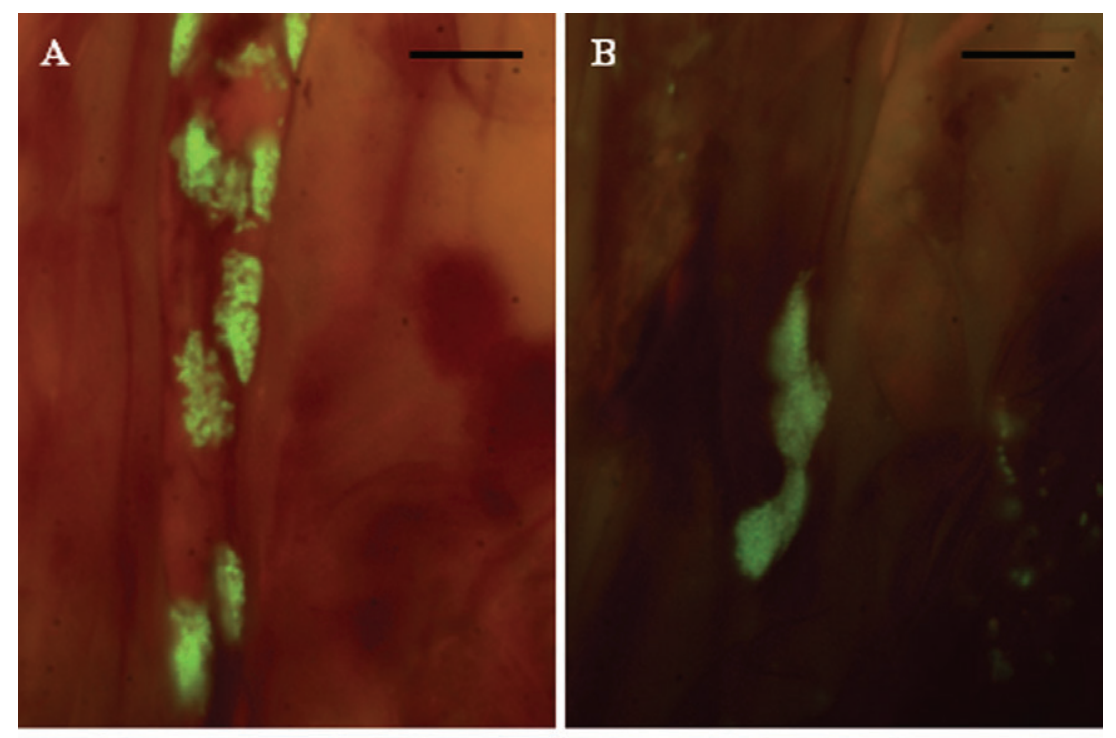

Fig. 3. Epifluorescence microscopy analysis of the colonization of the alfalfa rhizosphere by gfp-tagged F113 and V35. Roots were visualized 1 week after inoculation.

$A$ and B. F113.

C and D. V35.

No differences in shape, size, location or number of microcolonies were observed. Bar represents $5 \mu \mathrm{m}$
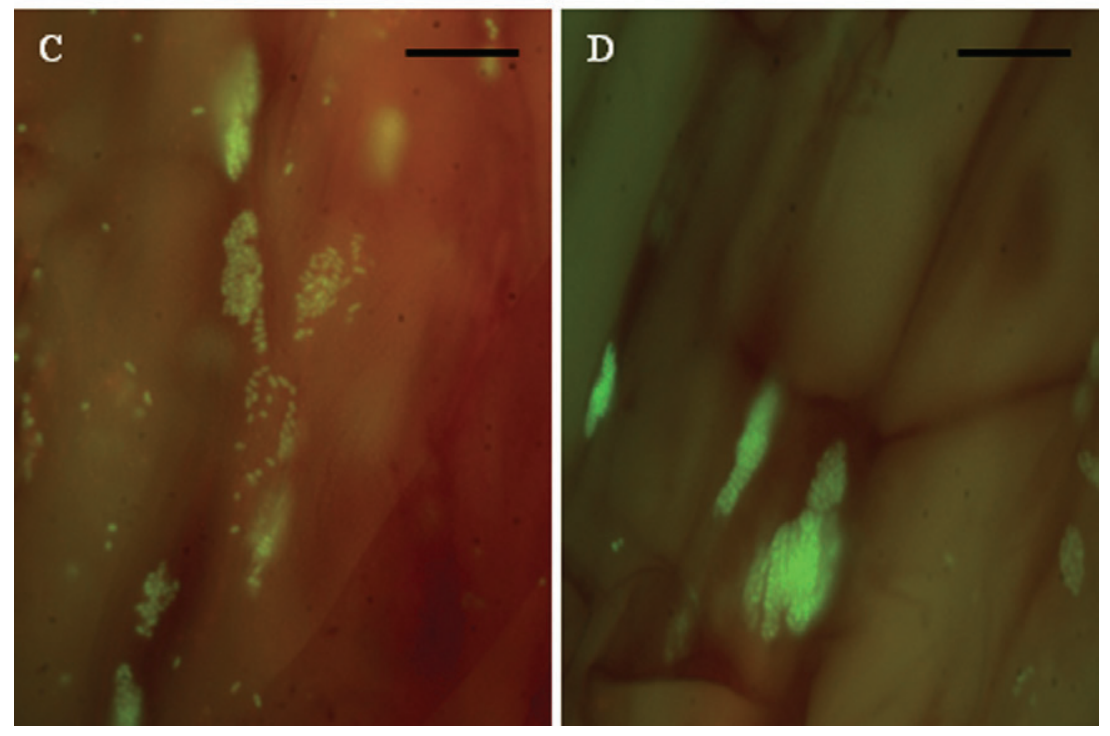

of specific m-RNAs. Mutants in the gacA and/or gacS genes are impaired in biofilm formation by $P$. aeruginosa (Parkins et al., 2001; Davies et al., 2007), Pseudomonas sp. (Choi et al., 2007) and a clinical strain of $P$. fluorescens (Rossignol et al., 2009). Here we have shown that in P. fluorescens F113 the Gac system is necessary for full biofilm formation. Furthermore, since a gacSsadBwspR triple mutant shows an additive phenotype for biofilm formation under all tested conditions, we can affirm that regulation through these three genes is independent, as we previously observed for swimming and swarming phenotypes (Navazo et al., 2009). We have also shown that in F113 gacS is not necessary for rhizosphere colonization or competitive colonization, as was previously reported for P. chlororaphis (Schmidt-Eisenlohr et al., 2003).

In a previous work (Martinez-Granero et al., 2006), we showed that when overexpressing the site-specific recombinases Sss and XerD and after rhizosphere passage, hypermotile phenotypic variants were selected. Here we have tested one of these variants (V35) for biofilm formation. V35 harbours a mutation on the gacS gene and additional un-identified mutations repressing motility, since the cloned gacS gene complements the swimming phenotype only partially (Martínez-Granero et al., 2006). We have shown here that V35 is affected in its ability to develop a fully structured mature biofilm on abiotic surfaces but not in rhizosphere colonization, either in the absence or in the presence of a wild-type competitor. Furthermore, both the triple GSW mutant and V35 were more competitive than the wild-type strain for root tip colonization. These results show that hypermotility constitutes an advantage for bacterial establishment on the root tip, an environment where the ability to form biofilms on abiotic surfaces seems not to be a relevant trait. Thus, the 

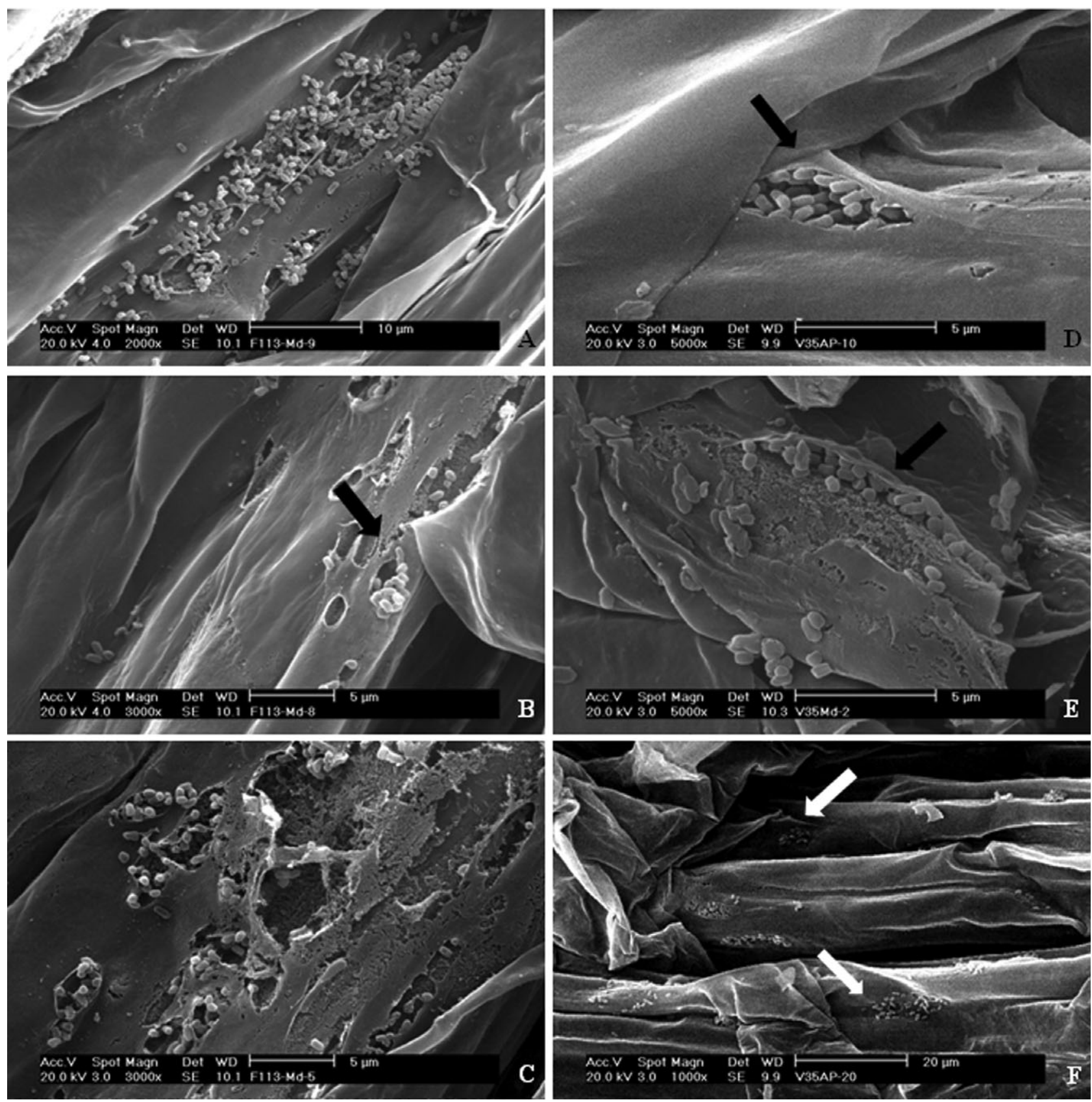

Fig. 4. Scanning microscopy analysis of the colonization of the alfalfa rhizosphere by F113 and V35.

A-C. F113.

D-F. V35.

No differences were observed in the colonization pattern of both strains. Note the mucigel layer holding the bacteria in the rhizoplane. Black arrows point to breaks in the mucigel, which allow the observation of bacterial cells. Cells are also observed when the mucigel is displaced (white arrows). Bacteria appear densely packed and no exopolysaccharide fibrils linking the bacterial cells were observed.

genetic determinants necessary to colonize abiotic surfaces and the plant rhizoplane by $P$. fluorescens appear to be different. In this sense, it has been proposed that colonization of plant and abiotic surfaces by $P$. putida follow distinct, although partially overlapping pathways (Yousef-Coronado et al., 2008). In P. putida, flagellar motility determines the distribution of cells along the root, but does not seem to have a significant impact on its overall fitness in the rhizosphere.

The results presented here also have biotechnological implications. In the selection of strains for biological control or plant growth promotion, the ability to form biofilms on abiotic surfaces is frequently tested, on the assumption that good biofilm producers will also be good

(c) 2010 Society for Applied Microbiology and Blackwell Publishing Ltd, Environmental Microbiology, 12, 3185-3195 
plant colonizers (Bais et al., 2004; Haggag and Timmusk, 2008; Rudrappa et al., 2008). Based on our results, this assumption is not necessarily correct, since strains unable to form biofilms on abiotic surfaces can displace isogenic, biofilm forming strains from a key colonization site as is the root tip.

A comparison between the colonization pattern of the wild-type strain and V35 did not reveal any differences. Both strains formed microcolonies on the rhizoplane, preferentially between epidermic cells, as reported before for the wild-type strain (Villacieros et al., 2003). Using scanning electron microscopy, we observed that bacterial cells were tightly packed in microcolonies and that the extracellular material typical of biofilms appeared to be absent. Instead, microcolonies were surrounded by a mucigel layer that holds the microcolony on the rhizoplane. Similar observations were made by Chin-A-Woeng and colleagues (1997). In that study, microcolonies surrounded by a plant derived mucigel were observed not only for $P$. fluorescens, but also for P. mendocina, P. putida, Xantomonas oryzae and Acidovorax facilis. The results presented here provide genetic evidence to these observations. However, these authors also noted that other rhizobacteria such as Rhizobium spp. and Acinetobacter radioresistens present different colonization patterns, being unable to form microcolonies on the rhizoplane. It has also been recently observed (Pliego et al., 2008) that two biocontrol pseudomonads show different colonization patterns on the same plant. These data highlight the differences in strategies followed by bacteria for rhizosphere colonization.

As a conclusion, the results reported here indicate that biofilms formed by $P$. fluorescens on abiotic surfaces and on the rhizoplane are not equivalent structures, since each seems to follow a different genetic programme. Therefore, the root-colonizing capacity of a bacterial strain cannot be generally inferred from its ability to form biofilms on abiotic surfaces under standard laboratory conditions.

\section{Experimental procedures}

\section{Bacterial strains and growth conditions}

Wild-type P. fluorescens F113 (Shanahan et al., 1992), F113 mutants (Navazo et al., 2009) and phenotypic variant 35 (V35) (Martinez-Granero et al., 2006) have been previously described. Pseudomonas fluorescens strains were grown with shaking in SA medium (Scher and Baker, 1982) overnight at $28^{\circ} \mathrm{C}$, except for biofilm formation assays, which were grown in Luria-Bertani (LB) medium. Escherichia coli strains were grown in LB medium with shaking overnight at $37^{\circ} \mathrm{C}$. When required, the followings antibiotics were added: rifampicin $100 \mu \mathrm{g} \mathrm{ml}^{-1}$, spectinomycin $100 \mu \mathrm{g} \mathrm{ml}^{-1}$, tetracycline $10 \mu \mathrm{g} \mathrm{ml}^{-1}$ (for $E$. coll) or $70 \mu \mathrm{g} \mathrm{ml}^{-1}$ (for P. fluorescens) and kanamycin $25 \mu \mathrm{g} \mathrm{ml}^{-1}$ (for $E$. coll) or $50 \mu \mathrm{g} \mathrm{ml}^{-1}$ (for $P$. fluorescens). The pDSK-GFPuv (Wang et al., 2007) and the pHC60 (Cheng and Walker, 1998) plasmids, expressing the green fluorescent protein ( $g f p)$, were mobilized to $P$. fluorescens by triparental mating, using pRK600 as the helper plasmid (Finan et al., 1986).

\section{Biofilm formation assays in multi-well plates}

A modification of the method of Fletcher (1977) was used. Exponentially growing cultures on LB medium were diluted to an $\mathrm{OD}_{600}$ of 0.04 . Approximately $100 \mu \mathrm{l}$ from each diluted culture was placed on a well of polyestirene or polypropylene multi-well plates that were incubated $8 \mathrm{~h}$ at $28^{\circ} \mathrm{C}$. Approximately $25 \mu \mathrm{l}$ of a crystal violet solution was added to each well for 15 min to allow the staining of adhered cells. Excess stain was eliminated by rinsing with water. Plates were air dried and $200 \mu \mathrm{l}$ of $95 \%$ ethanol was added to each well in order to extract crystal violet from cells. Destaining was performed overnight with shaking. After that, colour on plates was measured at $\mathrm{OD}_{590}$ with a microtiter plate reader. Every assay was performed eight times for each strain.

\section{Biofilm formation in flow cells}

Plasmids pDSK-GFPuv (Wang et al., 2007) or pHC60 (Cheng and Walker, 1998) were introduced in P. fluorescens strains by triparental mating and green fluorescence due to the presence of gfp was visualized by epifluorescence microscopy. A modification of the method of Sternberg and Tolker-Nielsen (Gjermansen et al., 2005) was used for biofilm formation under flow conditions, using LB diluted 1:10 as growth medium. Biofilms were grown at $30^{\circ} \mathrm{C}$ in three-chanel flow chambers (BioCentrum-DTU, Technical University of Denmark), using a Watson Marlow 205S peristaltic pump (Watson Marlow, Wilmington, MA, USA). Fresh overnight cultures were diluted to an $\mathrm{OD}_{600}$ of 0.5 , and $300 \mu \mathrm{l}$ was injected in the flow chamber. During the first hour, the flow was turned off in order to allow cells attach to the chamber; then, the flow was turned on and kept at a constant flow rate of $3.0 \mathrm{ml} \mathrm{h}^{-1}$, which corresponds to a Reynolds number of 0.02 (laminar flow conditions). Biofilm structures were visualized after 3, 6 and $24 \mathrm{~h}$ of growth with a Nikon C1 confocal laser scanning microscope. Images were analysed with the Imaris software (Bitplane), and biofilm parameters (biovolume, distribution, average thickness and maximum thickness) were calculated using COMSTAT (Heydorn et al., 2000). All data were compared using the statistics application software SPSS.

\section{Rhizosphere colonization and competition assays}

Alfalfa seeds were surface sterilized in $70 \%$ ethanol for 2 min and then in diluted bleach (1:5) for $15 \mathrm{~min}$ and rinsed thoroughly with sterile distilled water. Seed vernalization was performed at $4^{\circ} \mathrm{C}$ for $16 \mathrm{~h}$ followed by incubation in darkness at $28^{\circ} \mathrm{C}$ for 1 day. Germinated alfalfa seeds were sown in Leonard jar gnotobiotic systems (Villacieros et al., 2003) using perlite as the solid substrate and $8 \mathrm{mM} \mathrm{KNO}_{3}$ supplemented FP (Fahraeus, 1957) as the mineral solution. After 2 days, alfalfa seeds were inoculated with $c .10^{8}$ cells of the appropriate strains. In competition experiments, strains were 
inoculated at a $1: 1$ ratio. Plants were maintained under controlled conditions $\left(16 \mathrm{~h}\right.$ in the light at $25^{\circ} \mathrm{C}$ and $8 \mathrm{~h}$ in the dark at $18^{\circ} \mathrm{C}$ ) for 2 weeks. Whole plants were carefully extracted from the perlite and roots were excised and thoroughly washed with water to eliminate any perlite particle remaining attached to the root, or loosely attached bacteria. Bacteria were recovered from the rhizosphere by vortexing the roots tips (last centimetre of the main root) for 2 min in a tube containing FP medium and plating the appropriate dilutions on SA plates with the appropriate antibiotics. Every experiment was performed three times with three replicates each times, and every replicate contained at least 20 pooled plants.

\section{Fluorescence microscopy}

pDSK-GFPuv plasmid (Wang et al., 2007), harbouring a gene expressing green fluorescent protein, was introduced into $P$. fluorescens $\mathrm{F} 113$ and V35 by triparental mating. Alfalfa seeds were independently inoculated with $c .10^{8}$ of either strain, and were grown as described above. After 7 days, plants were collected, the root system excised and stained with $0.5 \%$ crystal violet during $1 \mathrm{~min}$. Antifading (Vectashield, Vector Laboratories) was added and slides were assembled. Slides were observed with an optical epifluorescence microscope (OLYMPUS BH2-RFCA) with a Leica-MTV-3 camera. Rhizosphere colonization fluorescence images of both pseudomonas strains were captured with $40 \times$ or $100 \times$ objectives. Images of GFP-labelled bacterial cells were obtained by using a filter set consisting of a 400 to $490 \mathrm{~nm}$ (BP490) bandpass exciter, a $505 \mathrm{~nm}$ dicroic filter and a $530 \mathrm{~nm}$ longpass emitter (EO530).

\section{Scanning electron microscopy}

Alfalfa plants were independently inoculated with the wildtype strain and the phenotypic variant V35 and grown for 7 days as indicated above. Plants were collected and the roots were excised. The main root was divided in three sections, proximal, middle and root-tip and were fixed in $2.5 \%$ glutaraldehyde for $2 \mathrm{~h}$, washed twice with $0.2 \mathrm{M}$ sodium cocodylate $(\mathrm{pH}=7.1)$ during $30 \mathrm{~min}$ and dehydrated through increasing ethanol concentrations $(10 \%, 30 \%, 50 \%, 70 \%$, $90 \%$ and $100 \%$ ). The fixed roots were subjected to critical point, mounted on stubs and gold coated. Samples were visualized using a scanning electron microscope Philips XL30.

\section{Acknowledgements}

We are grateful to Juan de Dios Alché for assistance with confocal laser microscopy and to Unidad de Microscopía Electrónica de Barrido (SiDI-UAM) for assistance with scanning microscopy. A.N. and F.Y.C. were recipients of a FPI fellowship from Ministerio de Ciencia e Innovación (MICINN, Spain). E.B and D.A.C. were recipients of a postgraduate research contract from Comunidad de Madrid. Research was funded by grants BIO2006-08596, BIO2009-08254 and BFU2007-64270 from MICINN and the research program MICROAMBIENTE-CM from Comunidad de Madrid.

\section{References}

Aguirre de Cárcer, D., Martín, M., Mackova, M., Macek, T., Karlson, U., and Rivilla, R. (2007a) The introduction of genetically modified microorganisms designed for rhizoremediation induces changes on native bacteria in the rhizosphere but not in the surrounding soil. ISME $J 1$ : 215-223.

Aguirre de Cárcer, D., Martín, M., Karlson, U., and Rivilla, R. (2007b) Changes in bacterial populations and in biphenyl dioxygenase gene diversity in a polychlorinated biphenylpolluted soil after introduction of willow trees for rhizoremediation. Appl Environ Microbiol 73: 6224-6232.

Bais, H.P., Fall, R., and Vivanco, J.M. (2004) Biocontrol of Bacillus subtilis against infection of Arabidopsis roots by Pseudomonas syringae is facilitated by biofilm formation and surfactin production. Plant Physiol 134: 307-319.

Brazil, G.M., Kenefick, L., Callanan, M., Haro, A., de Lorenzo, V., Dowling, D.N., and O'Gara, F. (1995) Construction of a rhizosphere pseudomonad with potential to degrade polychlorinated-byphenyls and detection of BPH geneexpression in the rhizosphere. Appl Environ Microbiol 61: 1946-1951.

Caiazza, N.C., and O'Toole, G.A. (2004) SadB is required for the transition from reversible to irreversible attachment during biofilm formation by Pseudomonas aeruginosa PA14. J Bacteriol 186: 4476-4485.

Capdevila, S., Martínez-Granero, F., Sánchez-Contreras, M., Rivilla, R., and Martín, M. (2004) Analysis of Pseudomonas fluorescens $\mathrm{F} 113$ genes implicated in flagellar filament synthesis and their role in competitive root colonization. Microbiology 150: 3889-3897.

Cassidy, M.B., Leung, K.T., Lee, H., and Treyors, J.T. (2000) A comparison of enumeration methods for culturable Pseudomonas fluorescens cells marked with green fluorescent protein. Microbiol Methods 40: 135-145.

Cheng, H.P., and Walker, G.C. (1998) Succinoglycan is required for initiation and elongation of infection threads during nodulation of alfalfa by Rhizobium meliloti. J Bacteriol 180: 5183-5191.

Chin-A-Woeng, T.F.C., de Priester, W., van der Bij, A.J., and Lugtenberg, B.J. (1997) Description of the colonization of a gnotobiotic tomato rhizosphere by Pseudomonas fluorescens biocontrol strain WCS365, using scanning electron microscopy. Mol Plant Microbe Interact 10: 79-86.

Choi, K.S., Veeraraqouda, Y., Cho, K.M., Lee, S.O., Jo, G.R., Cho, K., and Lee, K. (2007) Effect of gacS and gacA mutations on colony architecture, surface motility, biofilm formation and chemical toxicity in Pseudomonas sp. KL 28. J Microbiol 45: 492-498.

Davies, J.A., Harrison, J.J., Marques, L.L., Foglia, G.R., Stremick, C.A., Storey, D.G., et al. (2007) The GacS sensor kinase controls phenotypic reversion of small colony variants isolated from biofilms of Pseudomonas aeruginosa PA14. FEMS Microbiol Ecol 59: 32-46.

Dekkers, L.C., Mulders, I.H.M., Phoelich, C.C., Chin-AWoeng, T.F.C., Wijfjes, A.H.M., and Lugtenberg, B.J.J. (2000) The sss colonization gene of the tomato-Fusarium oxysporum F. sp radicis-lycopersici biocontrol strain Pseudomonas fluorescens WCS365 can improve root colonization of other wild-type Pseudomonas spp. bacteria. Mol Plant Microbe Interact 13: 1177-1183. 
Fahraeus, G. (1957) The infection of clover root hairs by nodule bacteria studied by simple glass technique. J Genet Microbiol 16: 374-381.

Finan, T.M., Kunkel, B., de Vos, G.F., and Signer, E.R. (1986) Second symbiotic megaplasmid in Rhizobium meliloti carrying exopolysaccharide and thiamine synthesis genes. J Bacteriol 167: 66-72.

Fletcher, A. (1977) The effects of culture concentration and age, time and temperature on bacterial attachment to polystyrene. Can J Microbiol 23: 1-6.

Gjermansen, M., Ragas, P., Sternberg, C., Molin, S., and Tolker-Nielsen, T. (2005) Characterization of starvationinduced dispersion in Pseudomonas putida biofilms. Environ Microbiol 7: 894-906.

Haas, D., and Defago, G. (2005) Biological control of soilborne pathogens by fluorescent pseudomonads. Nat Rev Microbiol 4: 307-319.

Haggag, W.M., and Timmusk, S. (2008) Colonization of peanut roots by biofilm-forming Paenibacillus polymyxa initiates biocontrol against crown rot disease. J Appl Microbiol 104: 961-969.

Hengge, R. (2009) Principles of c-di-GMP signalling in bacteria. Nat Rev Microbiol 7: 263-273.

Heydorn, A., Nielsen, A.T., Hentzer, M., Sternberg, C., Givskov, M., Ersbøll, B.K., and Molin, S. (2000) Quantification of biofilm structures by the novel computer program COMSTAT. Microbiology 146: 2395-2407.

Hickman, J.W., Tifrea, D.F., and Harwood, C.S. (2005) A chemosensory system that regulates biofilm formation through modulation of cyclic diguanylate levels. Proc Natl Acad Sci USA 102: 14422-14427.

Hiltner, L. (1904) Über neuere Erfahrungen und Probleme auf dem Gebiete der Bodenbakteriologie unter besonderer Berücksichtigung der Gründüngung und der Brache. Arb DLG 98: 59-78.

Kuchma, S.L., Brothers, K.M., Merritt, J.H., Liberati, N.T., Ausubel, F.M., and O'Toole, G.A. (2007) BifA a cyclic-DiGMP phosphodiesterase, inversely regulates biofilm formation and swarming motility by Pseudomonas aeruginosa PA14. J Bacteriol 189: 8165-8178.

Lazazzera, B. (2005) Lessons from DNA microarray analysis: the gene expression profile of biofilms. Curr Opin Microbiol 8: 222-227.

Lugtenberg, B.J., and Dekkers, L.C. (1999) What makes Pseudomonas bacteria rhizosphere competent? Environ Microbiol 1: 9-13.

Lugtenberg, B.J., Dekkers, L.C., and Bloemberg, G.V. (2001) Molecular determinants of rhizosphere colonization by Pseudomonas. Ann Rev Phytopathol 39: 461-490.

Martínez-Granero, F., Rivilla, R., and Martín, M. (2006) Rhizosphere selection of highly motile phenotypic variants of Pseudomonas fluorescens with enhanced competitive colonization ability. Appl Environ Microbiol 72: 3429-3434.

Merritt, J.H., Brothers, K.M., Kuchma, S.L., and O'Toole, G.A. (2007) SadC reciprocally influences biofilm formation and swarming motility via modulation of exopolysaccharide production and flagellar function. J Bacteriol 189: 8154-8164.

Naseby, D.C., and Lynch, J.M. (1998) Impact of wild-type and genetically modified Pseudomonas fluorescens on soil enzyme activities and microbial population structure in the rhizosphere of pea. Mol Ecol 7: 617-625.
Navazo, A., Barahona, E., Redondo-Nieto, M., MartínezGranero, F., Rivilla, R., and Martín, M. (2009) Three independent signalling pathways repress motility in Pseudomonas fluorescens F113. Microb Biotechnol 2: 489-498.

Normander, B., Hendriksen, N.B., and Nybroe, O. (1999) Green fluorescent protein-marked Pseudomonas fluorescens: localization, viability, and activity in the natural barley rhizosphere. Appl Environ Microbiol 65: 46464651.

O'Toole, G.A., and Kolter, R. (1998a) Flagellar and twitching motility are necessary for Pseudomonas aeruginosa biofilm development. Mol Microbiol 30: 295-304.

O'Toole, G.A., and Kolter, R. (1998b) Initiation of biofilm formation in Pseudomonas fluorescens WCS365 proceeds via multiple, convergent signalling pathways: a genetic analysis. Mol Microbiol 28: 449-461.

Parkins, M.D., Ceri, H., and Storey, D.G. (2001) Pseudomonas aeruginosa GacA, a factor in multihost virulence, is also essential for biofilm formation. Mol Microbiol 40: 1215-1226.

Pliego, C., de Weert, S., Lamers, G., de Vicente, A., Bloemberg, G., Cazorla, F.M., and Ramos, C. (2008) Two similar enhanced root-colonizing Pseudomonas strains differ largely in their colonization strategies of avocado roots and Rosellinia necatrix hyphae. Environ Microbiol 10: 32953304.

Ramos, C., Molina, L., Mølbak, L., Ramos, J.L., and Molin, S. (2000) A bioluminescent derivative of Pseudomonas putida KT2440 for delibérate release into the environment. FEMS Microbiol Ecol 34: 91-102.

Rossignol, G., Sperandio, D., Guerrillon, J., Duclairoir Poc, C., Soum-Soutera, E., Orange, N., et al. (2009) Phenotypic variation in the Pseudomonas fluorescens clinical strain MFN1032. Res Microbiol 160: 337-344.

Rudrappa, T., Biedrzycki, M.L., and Bais, H.P. (2008) Causes and consequences of plant associated biofilms. FEMS Microbiol Ecol 64: 153-166.

Sánchez-Contreras, M., Martín, M., Villacieros, M., O'Gara, F., Bonilla, I., and Rivilla, R. (2002) Phenotypic selection and phase variation occur during alfalfa root colonization by Pseudomonas fluorescens F113. J Bacteriol 184: 15871596.

Scher, F.M., and Baker, R. (1982) Effects of Pseudomonas putida and a synthetic iron chelator on induction of soil supressiveness to Fusarium wilt pathogens. Phytopathology 72: 1567-1573.

Schmidt-Eisenlhr, H., Gast, A., and Baron, C. (2003) Inactivation of gacS does not affect the competitiveness of Pseudomonas chlororaphis in the Arabidopsis thaliana rhizosphere. Appl Environ Microbiol 69: 1817-1826.

Shanahan, P., Borro, A., O'Gara, F., and Glennon, J.D. (1992) Isolation, trace enrichment and liquid-chromatographic analysis of diacetylphloroglucinol in culture and soil samples using UV and amperometric detection. J Chromatogr 606: 171-177.

Villacieros, M., Power, B., Sánchez-Contreras, M., Lloret, J., Oruezábal, R.I., Martín, M., et al. (2003) Colonization behaviour of Pseudomonas fluorescens and Sinorhizobium meliloti in the alfalfa (Medicago sativa) rhizosphere. Plant Soil 251: 47-54. 
Villacieros, M., Whelan, C., Mackova, M., Molgaard, J., Sánchez-Contreras, M., Lloret, J., et al. (2005) Polychlorinated biphenyl rhizoremediation by Pseudomonas fluorescens F113 derivatives, using a Sinorhizobium meliloti nod system to drive bph gene expression. Appl Environ Microbiol 71: 2687-2694.

Wang, K., Kang, L., Anand, A., Lazarowits, G., and Mysore, K.S. (2007) Monitoring in planta bacterial infection at both cellular and whole-plant levels using the green fluorescent protein variant GFPuv. New Phytol 174: 212-223.

de Weert, S., Vermeiren, H., Mulders, I.H.M., Kuiper, I., Hendrickx, N., Bloemberg, G.V., et al. (2002) Flagelladriven chemotaxis towards exudate components is an important trait for tomato root colonization by Psuedomonas fluorescens. Mol Plant Microbe Interact 15: 11731180.

Yee, D.C., Maynard, J.A., and Wood, T.K. (1998) Rhizoremediation of trichloroethylene by a recombinant, rootcolonizing Pseudomonas fluorescens strain expressing toluene ortho-monooxygenase constitutively. Appl Environ Microbiol 64: 112-118.
Yousef-Coronado, F., Travieso, M.L., and Espinosa-Urgel, M. (2008) Different, overlapping mechanisms for colonization of abiotic and plant surfaces by Pseudomonas putida. FEMS Microbiol Lett 288: 118-124.

\section{Supporting information}

Additional Supporting information may be found in the online version of this article:

Fig. S1. 3-D reconstruction of the biofilm formed by Pseudomonas fluorescens $\mathrm{F} 113$ in flow cells after $24 \mathrm{~h}$ observed by confocal laser microscopy.

Fig. S2. 3-D reconstruction of the biofilm formed by Pseudomonas fluorescens F113 Variant 35 in flow cells after $24 \mathrm{~h}$ observed by confocal laser microscopy.

Please note: Wiley-Blackwell are not responsible for the content or functionality of any supporting materials supplied by the authors. Any queries (other than missing material) should be directed to the corresponding author for the article. 